\title{
Doctors' groups a roadblock to reform, researchers say
}

Published at www.cmaj.ca on May 31

$\mathrm{M}$ edical associations often pose a powerful barrier to health care reform in Canada, according to researchers participating in a web seminar hosted by the Canadian Health Services Research Foundation.

Organizations representing the medical profession have played a key role in preventing or significantly slowing down "big bang" reforms, said Harvey Lazar, an adjunct professor for the School of Public Administration and senior research associate for the Centre for Global Studies at the University of Victoria in British Columbia.

Lazar, lead investigator of a crossprovincial comparison of health care policy reform in Canada between 1990 and 2003, said the results of that project reveal two major obstacles to systemic change. "One was the Canadian public's attachment to the existing health care model. ... [The other was] insider interests that coalesced around and benefited from that model."

According to Lazar, physicians' groups were "clearly the most powerful" of those insider interests, thanks in part to sinking public confidence in government.

"Public opinion data shows that the public have confidence in doctors but not in government and the gap between them is as large as about 30 to 40 percentage points in some polls."

That gap and the bitter legacy of medical strikes have given organized medicine the political clout to block reform proposals, particularly those that "would either narrow the professional autonomy of physicians or conflict with their preferred system of financial compensation," said Lazar.

As an example of that clout, Lazar cited failed attempts to reform the fee-forservice payment model, which reimburses doctors for each of their clinical activities and has been criticized for discouraging physicians from offering costeffective care in favour of volume.

"There's been a consensus for maybe 30 years that fee-for-service as a method

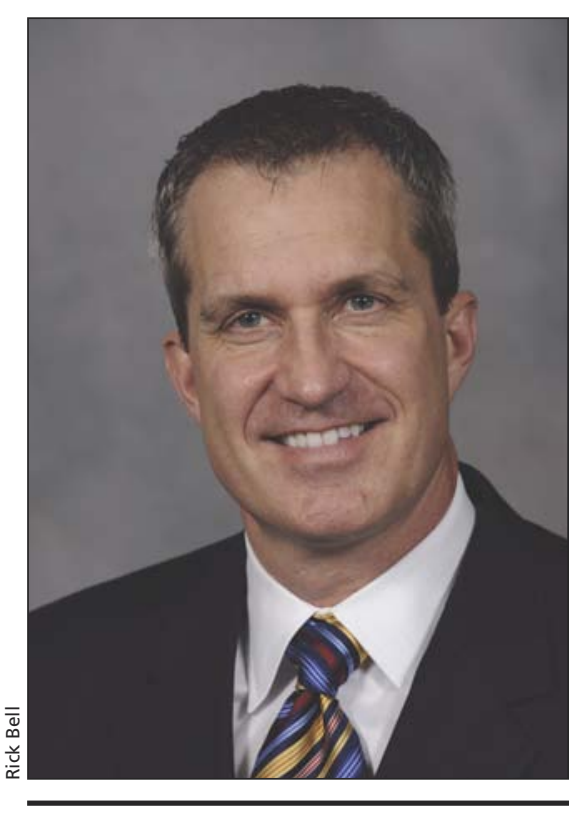

Dr. Mark MacLeod, president of the Ontario Medical Association, says those who claim that doctors have been a barrier to health reform are "simply misinformed."

of compensating primary care physicians is not ideal," he said. "But doctors have been remarkably successful in their negotiations with provincial health ministries not to rush [the reform] process."

Lazar suggested the practical consequence of this kind of roadblock is a slower rate of change and a "meagre" body of reform.

But Dr. Mark MacLeod, president of the Ontario Medical Association, counters that Lazar is "simply misinformed."

"The Ontario Medical Association is willing to work with all partners who seek to improve the quality and sustainability of the health care system," he says. "The association has helped lead health innovation on a number of fronts, including primary care reform, anaesthesia care teams, and physician assistant pilot programs."

The Saskatchewan Medical Association likewise points to its own involvement in a plan to drop surgical wait times as an example of "government, physicians and all health care professionals working collaboratively."
"Where physicians have questioned reform, it was because the [proposed] model was too rigid, not functional, and was designed to be imposed from the top down," says Dr. Martin Vogel, CEO of the association. "One size will not fit all, but we will help create the toolkit that communities can use to build the model that best fits their circumstance."

Yet, experts at the May 27 web seminar questioned the necessity of engaging the medical profession in the reform agenda.

"You don't need collaboration, you just need indifference," said PierreGerlier Forest, coinvestigator of the cross-provincial study, president of the Pierre Elliott Trudeau Foundation and former assistant deputy minister of Health Canada. "The important point is that they feel the reform agenda that has been put on the table is compatible with the core bargain between the profession and the state."

The little reform that did occur between 1990 and 2003 was largely driven by factors outside the health sector, added Forest. "Political change and fiscal crisis opened the proverbial window of opportunity in six of the seven cases where reform occurred."

Lazar also predicted the next federal election and the 2014 sunset on fiscal arrangements between the federal and provincial governments will create a perfect storm for health care reform in the next few years.

The comparison study aimed to improve prospects for meaningful health care reforms by analyzing recent policies in Alberta, Saskatchewan, Ontario, Quebec and Newfoundland and Labrador. It was funded by the Canadian Institutes of Health Research and Health Canada, and is being conducted by a team of 12 researchers based at six universities. Though the 30 case studies comprising the project have been completed, the findings have yet to be published. — Lauren Vogel, CMAJ

DOI:10.1503/cmaj.109-3271 